\title{
Ficção e realidade na Arquitetura Radical Italiana
}

\author{
Fiction and Reality in Italian Radical Architecture
}

\section{Ficción y realidad en la Arquitectura Radical Italiana}

\begin{tabular}{c} 
Bárbara Silva * \\
\hline http://dx.doi.org/10.22409/poiesis.1931.39-60
\end{tabular}

RESUMO: O seguinte ensaio propõe uma leitura dos projetos utópicos produzidos no final dos anos 1960 por dois grupos da chamada arquitetura radical italiana: Archizoom e Superstudio. A sua produção envolveu projetos que nunca quiseram sair do papel ou configurar visões de um futuro alarmante. O objetivo era, por um lado, provocar uma reflexão crítica sobre o fracasso dos ideais da arquitetura e do urbanismo moderno e, por outro, estabelecer uma relação irônica com uma sociedade demasiado confiante nas virtudes do consumo e da tecnologia. Seus projetos, muitas vezes considerados como fantasias tecnológicas ou meros exercícios gráficos, tiveram uma inesperada repercussão na crítica arquitetônica dos anos 1970. Nosso objetivo é decodificar as intenções presentes das produções utópicas de Archizoom e Super-studio assim como entender qual foi a sua repercussão, através de uma análise critica de dois projetos: No-Stop City (1968-1972) do grupo Archizoom e Monumento Continuo (19691970) do grupo Superstudio.

PALAVRAS-CHAVE: utopia; ficção; Archizzom; Superstudio; pós-moderno

\footnotetext{
* Barbara Silva é Arquiteta pela Universidade de Coimbra (2004), Doutora em Teoria e Crítica de Projeto pela Universidade Politécnica de Madrid (2016) e Professora do Departamento de Arquitetura e Urbanismo da PUC, Rio de Janeiro. E-mail: bs.barbarasilva@gmail.com
} 
ABSTRACT: The following essay is a critical examination of the utopian projects produced in the late 1960 s by two groups of so-called Italian radical architecture: Archizoom and Superstudio. Their work involved projects that never wanted to get out of the paper, or shape visions of an alarming future. The aim was, on the one hand, to provoke a critical reflection on the failure of the ideals of architecture and modern urbanism and, on the other hand, to establish an ironic relationship with a society too confident in the virtues of consumption and technology. Their projects, often considered as technological fantasies or mere graphic exercises, had an unexpected repercussion on the architectural criticism of the 1970s. Our objective is to decode the intentions of the utopian productions of Archizoom and Superstudio as well as to understand what was its repercussion, through a critical analysis of two projects: No-Stop City (1968 - 1972) of the group Archizoom and Monumento Continuo (1969 - 1970) of the group Superstudio.

KEYWORDS: utopia; fiction; Archizzom; Superstudio; postmodern

RESUMEN: El siguiente ensayo propone una lectura de los proyectos utópicos producidos a finales de los años 1960 por dos grupos de la llamada arquitectura radical italiana: Archizoom y Superstudio. Su producción involucró proyectos que nunca quisieron salir del papel o configurar visiones de un futuro alarmante. El objetivo era, por un lado, provocar una reflexión crítica sobre el fracaso de los ideales de la arquitectura y del urbanismo moderno y, por otro, establecer una relación irónica con una sociedad demasiado confiada en las virtudes del consumo y de la tecnología. Sus proyectos, muchas veces considerados como fantasías tecnológicas o meros ejercicios gráficos, tuvieron una inesperada repercusión en la crítica arquitectónica de los años 1970. Nuestro objetivo es decodificar las intenciones de las producciones utópicas de Archizoom y Superstudio así como entender cuál fue su repercusión, a través de un análisis crítico de los proyectos: No-Stop City (1968 - 1972) del grupo Archizoom y Monumento Continuo (1969 - 1970) del grupo Superstudio.

PALABRAS CLAVE: utopia; ficción; Archizzom; Superstudio; posmoderno

Como citar: SILVA, Bárbara. Ficção e realidade na Arquitetura Radical Italiana. Poiésis, Niterói, v. 19, n. 31, p. 39-60, jan./jun. 2018. doi: http://dx.doi.org/10.22409/poiesis.1931.39-60

Poiésis, Niterói, v. 19, n. 31, jan./jun. 2018. 


\section{Ficção e realidade na Arquitetura Radical Italiana}

Introdução

Muitos pensam na arquitetura radical como um movimento de contestação que, por não estar integrado no sistema, criou um espaço separado da realidade. Nada é mais errado. 0 movimento radical agiu dentro e não fora do sistema. - Victor Papanek, 1995, p. 195.

No início do século $\mathrm{XX}$, o movimento moderno adotou a lógica mecânica e racional do sistema de produção industrial, como modelo de organização das cidades e da sociedade. Porém, a partir dos anos 1950 admite-se a existência de outra lógica, mais complexa e subjetiva, ligada ao consumo de massas fortemente estimulado pelo sistema capitalista. Esta nova condição social, econômica e cultural vem questionar a legitimidade dos princípios de ordem e de harmonia da arquitetura e do urbanismo moderno, colocando todo um pensamento em crise. É neste contexto que em 1966 Robert Venturi e Denise Scott 
Brown escrevem o livro Complexidade e Contradição em Arquitetura, ao qual se segue em 1972 Learning from Las Vegas. Ambos sugerem uma maneira de ler a realidade que consiste na constatação de que a complexidade do mundo físico e social não é uma condição provisória - destinada a desaparecer dentro da ordem racional da produção industrial mas sim, fruto da própria industrialização que crescia de forma descontrolada. Na concepção de Venturi e Scott Brown (1982), o futuro seria cada vez mais complexo, porque o desenvolvimento industrial, dentro da lógica capitalista, tendia a atuar não na ordem, mas sim na desordem.

Em cinquenta anos de história passava-se de uma sociedade da máquina para uma sociedade de consumo na qual os valores estavam completamente invertidos: no lugar da fábrica estava o supermercado, no lugar da produção estava o consumo. As tentativas de criar uma sociedade homogênea, harmoniosa e funcional começam a ser abandonadas em prol do reconhecimento de uma sociedade heterogênea e contraditória que emergia a grande velocidade. Desse modo, a complexidade passa a ser a nova categoria de referência da arquitetura e do urbanismo que, ao contrário do racionalismo, pretendia acolher a diversidade, as emoções, as dúvidas e os sonhos. (PUGLISI, 1999 p. 52-54) Conforme proposta de Lyotard (1989), no final dos anos 1960 assistimos à transição do período moderno para o pós-moderno que representa a passagem entre dois momentos: o momento das velhas conviç̧ões representadas pelo pensamento racionalista e o momento das novas convicções, no qual a dúvida, a subjetividade, a complexidade o transitório, o fugidio e o efêmero formam as bases de um novo agir.

\section{Contexto}

Os anos sessenta são marcados por um ambiente de contestação contra a monotonia da visão universal do mundo moderno - geralmente percebido como positivista, tecnocêntrico e racionalista - e pela intensa desconfiança de todos os discursos universais ou totalizantes. É nesse contexto que surgem vários grupos de arquitetos que produzem um vasto conjunto de projetos utópicos, cujo objetivo era provocar uma discussão e um pensamen-

Poiésis, Niterói, v. 19, n. 31, jan./jun. 2018. 
to crítico sobre a condição e o papel da arquitetura e do urbanismo moderno na sociedade atual. Entre eles estão, os Metabolistas no Japão, os Archigram em Inglaterra, Hans Hollein e Walter Pichler na Áustria.

O grupo Metabolista formou-se em 1960, pelos jovens arquitetos Fumihiko Maki, Masato Otaka, Kiyonori Kikutake, Kisho Kurokawa e o crítico de arquitetura Noboru Wakazoe. No mesmo ano de sua formação, redigiram um manifesto, estabelecendo suas ideias, intitulado Metabolism: A Proposal for a New Urbanism, que foi apresentado na World Design Conference em Tóquio com o apoio de dois conceituados arquitetos: Kenzo Tange e Arata Isozaki.

A ideologia e os projetos utópicos realizados pelos Metabolistas defendiam a "cidade como organismo vivo" em contraponto à "cidade como máquina" gerada pelo urbanismo moderno:

O homem vive num imprevisível sistema de relações que não encontra no ambiente construído respostas convincentes; as cidades mal se adaptam às condições de vida modernas; as estruturas fixas e imutáveis não conseguem interagir com a realidade fluída, dinâmica em constante mutação, feita de relações funcionais e fluxos de comunicação. A procura da ordem e da harmonia priva a vida urbana da sua autenticidade. (PUGLISI, 1999 p. 69)

O grupo protestava ativamente contra o modernismo estático dos CIAM e contra academias e instituições. Os seus projetos utópicos propunham cidades flexíveis e transformáveis cujo objetivo era solucionar o problema de superpopulação do seu país. Para isso desenharam edifícios verticais aos quais iam sendo acopladas células de habitação préfabricadas. Megaestruturas que frequentemente estavam associadas a noções como adaptabilidade, flexibilidade, multifuncionalidade. (FRAMPTON, 1997) Um dos poucos edifícios construídos segundo esses princípios foi a torre para solteiros Nagakin em Tóquio. Projetada por Kurokawa em 1971, foi pensada para poder "crescer" e acoplar novas "cápsulas" sempre que fosse necessário. (Fig. 1) 


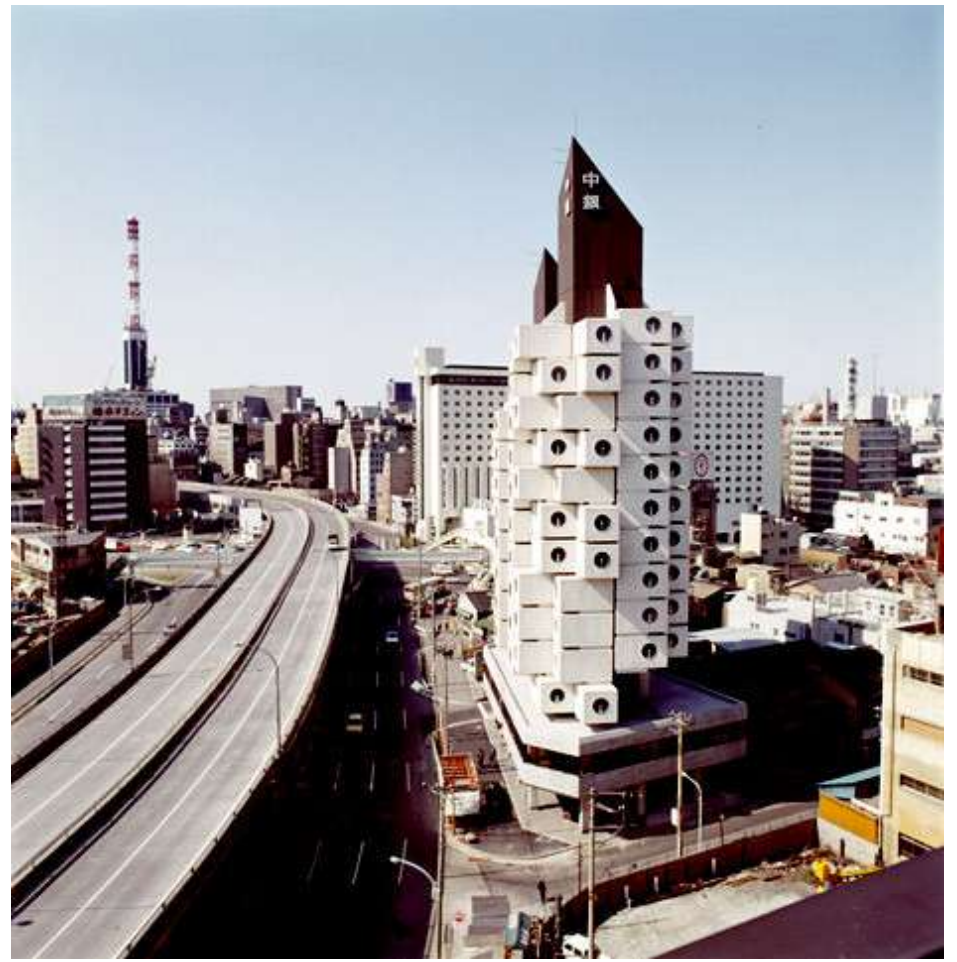

Fig. 1 - Kisho Kurokawa

Torre Nagakin, Tóquio, 1971.

(Fonte: AD Classics, (c) Arcspace)

Poiésis, Niterói, v. 19, n. 31, jan./jun. 2018. 
O grupo Metabolista japonês teve uma forte influência no modo de pensar e atuar do grupo inglês Archigram, formado em 1961 por Peter Cook, Dennis Crompton, Warren Chalk, David Greene, Ron Herron e Mike Webb. O nome vem da junção de duas palavras: architecture e telegram. Inicialmente o grupo se juntou para fundar uma revista, mas rapidamente se estabeleceu como nome de um coletivo de arquitetos que produziam projetos controversos e utópicos sobre a relação entre tecnologia, consumo, sociedade e arquitetura. Segundo Dominique Rouillard (1994), o Archigram foi talvez o primeiro grupo a pensar a arquitetura como um fenômeno de comunicação. Eles se lançaram no mercado como um produto da mídia, no qual suas ideias utópicas foram difundidas de maneira estratégica. Além da revista, eles propagaram o resultado de suas criações em exposições, através de happenings, instalações e outros meios que hoje são comuns, mas que na época era o que havia de mais novo no universo das artes e da comunicação.

O grupo produziu projetos que, como os Metabolistas, utilizavam os conceitos de megaestrutura para desenhar o território. Os que mais se destacam são: Plug-in City e Walking City, ambos realizados em 1964. A Plug-in City é um projeto utópico que representa uma cidade definida por uma aglomeração de megaestruturas que se conectam entre si como um complexo sistema de rede elétrica. (Fig. 2)

Dentro dessas megaestruturas estão localizadas as chamadas "células funcionais", destinadas a atender as necessidades da população como hospitais, comércio, apartamentos, restaurantes, serviços etc. Projetadas sob os princípios de flexibilidade e de substituição, essas "células" eram pensadas para ter certa durabilidade. Por exemplo: as células destinadas à habitação tinham uma vida útil de 40 anos, as de comércio durariam entre cinco e oito anos. A moradia ou o espaço de morar era visto como um dispositivo para ser levado pelo seu proprietário para onde quer que ele fosse e as cidades eram vistas como engrenagens de um motor na quais o habitante poderia plugar ou inserir sua unidade habitacional. (COOK, 1972) O objetivo era transmitir a ideia de que a cidade era um organismo vivo em constante atualização. Uma cidade pensada como um sistema infinito de fluxos, energias, imagens e produtos que, de forma radical, apresenta - per absurdum - 
uma crítica ao capitalismo e à sociedade de consumo de massas nos quais o homem desaparece a favor de um "sistema".

A Walking City também representa uma cidade definida por várias megaestruturas, mas introduzia uma inovação: elas se moviam. Com quatrocentos metros de comprimento e duzentos e vinte de altura, essas gigantescas estruturas estavam apoiadas em oito patas com rodas que Ihes permitiam a mobilidade. Eram uma espécie de máquinas com inteligência artificial, que se moviam livremente pelo mundo. Deste modo, as cidades podiam se conectar entre si, para formar uma espécie de "metrópole andante". (Fig. 3)

A Walking City simbolizava um futuro no qual não existiam fronteiras, no qual os limites são abandonados em favor de um estilo de vida nômade. O desenho destas estranhas estruturas era tão real que chegava a assustar quem o analisava, talvez por acreditarem que algum dia esse fenômeno pudesse mesmo acontecer... (PUGLISI, 1999 p.69-71)

\section{Arquitetura Radical Italiana}

A arquitetura radical italiana tem início em Florença, em 1963, quando se inicia, nas Faculdades de Arquitetura, um debate cultural e ideológico sobre o significado e a função da disciplina de projeto. Seguindo o eco do que acontecia na Europa, em especial na Inglaterra, as universidades italianas iniciam uma espécie de movimento reformador em oposição a uma cultura acadêmica que continuava a operar fora da realidade. Segundo Tafuri (1986), esta nova realidade, que se começou a delinear desde o segundo pós guerra, não aceitava a pretensão da arquitetura moderna de querer atingir soluções definitivas aos problemas do espaço e do habitar; por isso propunha uma aproximação real aos problemas, baseada na experimentação e na relação com as disciplinas artísticas, literárias. É neste ambiente de contestação aos princípios de ordem e de harmonia da arquitetura moderna que se formam, em Florença, os grupos de arquitetura radical italiana: Archizoom (1966) e Superstudio (1966) ${ }^{1}$.

Poiésis, Niterói, v. 19, n. 31, jan./jun. 2018. 


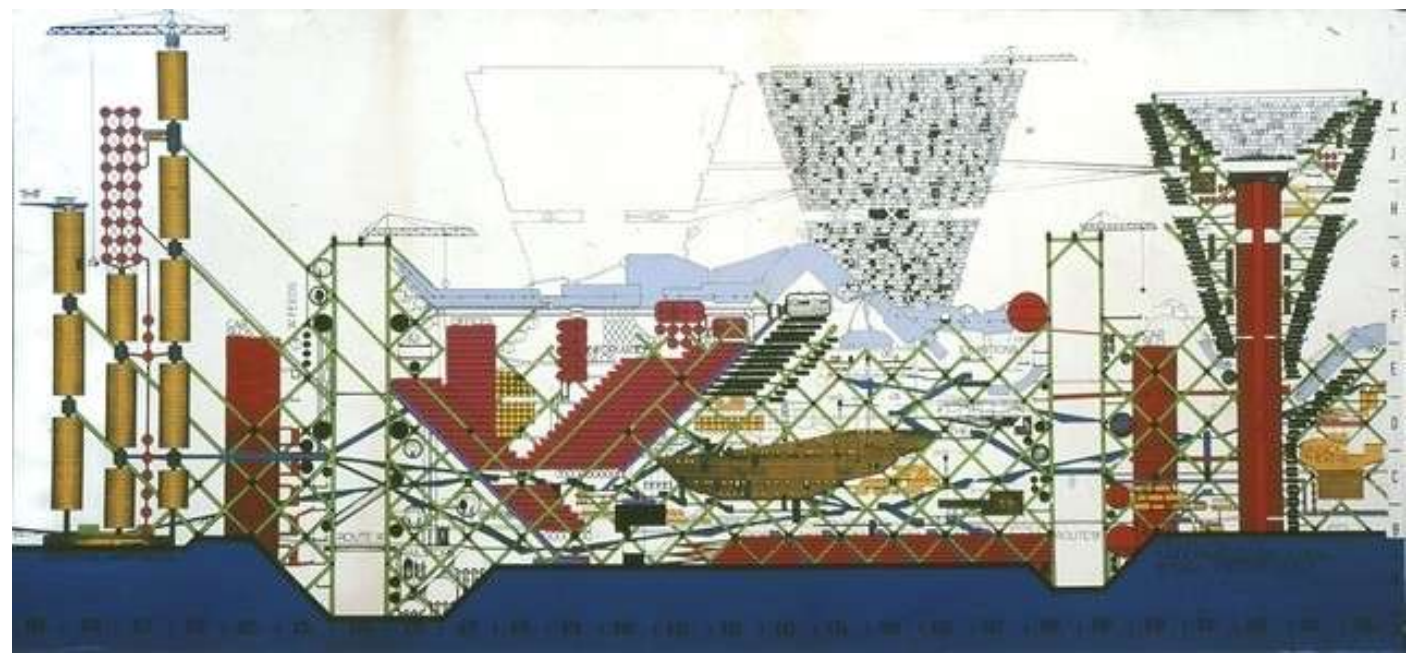

Fig. 2 - Peter Cook, Archigram

Plug-In City, 1964

(Fonte: Archigram Archives) 


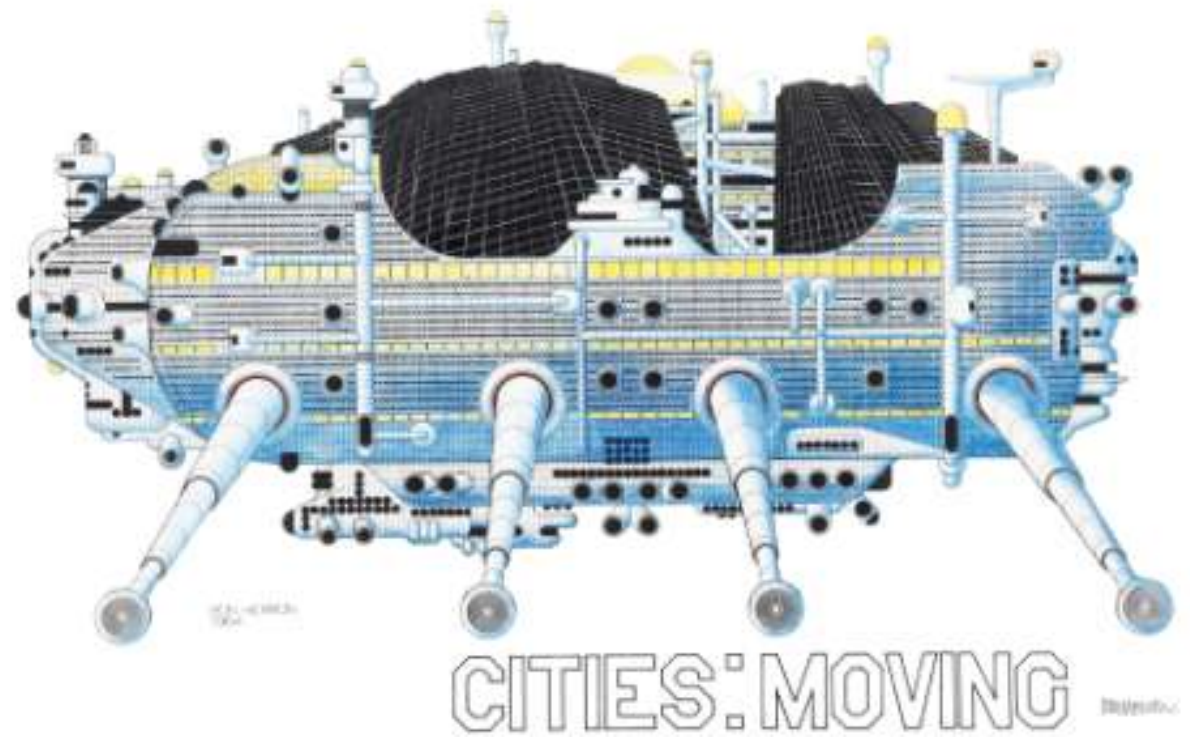

Fig. 3 - Ron Herron, Archigram

Walking City, 1964

(Fonte: Archigram Archives)

Poiésis, Niterói, v. 19, n. 31, jan./jun. 2018. 


\section{Archizoom e a No-Stop City}

O grupo Archizoom foi um escritório de design e arquitetura fundado em Florença, em 1966. Os membros fundadores eram Andrea Branzi, Gilberto Corretti, Paolo Deganello e Massimo Morozzi. Posteriormente, juntaram-se ao grupo Dario Bartolini e Lucia Bartolini. Dos integrantes, o que mais se destacava era Andrea Branzi (1938). Estudou em Florença em um ambiente influenciado pela constante crítica teórica patrocinada por personagens como Michelucci, Leonardo Ricci e Umberto Eco. Em 1964, na Biennale di Venezia, Branzi conheceu os trabalhos do grupo Archigram e a Pop Art. A importância da cultura pop para os grupos radicais italianos está no elevado nível de realismo que representa. Realismo que observa o mundo em sua versão mais comercial e mais vulgar e se relaciona com a cultura consumista e não com a cultura da produção (ao contrário do movimento moderno): "A linguagem da cultura consumista e dos mass media passa a ser a nova linguagem e as novas potencialidades do projeto". (RATTAZZI, 1997, p. 61)

A produção dos Archizoom pode parecer, em um primeiro momento, ligada às estratégias do grupo Archigram, mas a diferença substancial está no modo de interpretar a tecnologia. Os Archizoom rejeitavam a tecnologia como elemento fundamental na arquitetura, enquanto os Archigram celebram uma espécie de sociedade totalmente mecanizada, na qual a arquitetura se assemelha às engrenagens de um motor ou a uma rede elétrica. Para esses últimos, a técnica transforma-se em algo fantástico e espetacular. Este fenômeno não acontece com os Archizoom. O grande tema de sua produção está na tentativa de integrar o modelo de consumo de massas na construção de um novo modelo tecnológico de metrópole e na construção de uma narrativa que utiliza o poder de atração das imagens para comunicar, transmitir ideias e produzir um pensamento crítico sobre o papel da arquitetura na sociedade: "hoje a arquitetura realiza territórios no espaço, que ultrapassam a ocupação do solo. Durante muito tempo a arquitetura foi considerada uma arte plástica, para mim agora é uma arte narrativa". (RATTAZZI, 1997, p. 66)

As produções dos Archizoom refletiam a busca por uma nova abordagem do ambiente urbano, através de propostas altamente flexíveis, nas quais a arquitetura era assumida co- 
mo um elemento abstrato. Uma das produções mais emblemáticas do grupo é a No-Stop City, produzida entre 1969 e 1970. O projeto era definido por uma estrutura residencial contínua e homogênea, constituída por uma infinidade de edifícios subterrâneos, climatizados e iluminados artificialmente. Todos os pisos dos edifícios eram definidos por uma planta livre, ligados por elevadores que eram o único modo de aceder a superfície. Nos primeiros pisos estavam localizados os parques de estacionamento e as zonas de tráfego. A seguir existia uma zona verde, depois pisos de habitação (que eram uma espécie de "contentores"), depois serviços, comércio, cargas e descargas, autoestradas e comboios. (Fig. 4.1 e 4.2)

Foi umas das primeira tentativas de integração da cidade e do urbanismo dentro da lógica do consumo de massas, representada como um conjunto de necessidades e de funções que levava até ao limite a lógica do supermercado e do centro comercial (shooping), dentro da qual a arquitetura deixava de existir. Era a imagem de uma cidade sem arquitetura, cujo funcionamento era igual ao dos grandes centros comerciais: sem luz e sem ventilação naturais, sem nenhuma relação com o exterior, repleta de contentores indiferenciados. Um projeto de caráter utópico que apresentava um modo de pensar a arquitetura e o urbanismo totalmente integrado no sistema de consumo de massas:

A arquitetura radical era radical, era contra todos os velhos valores do movimento moderno que se opunham ao consumismo. De fato usa as grandes superfícies comerciais e industriais como nova arquitetura. Defendia a total integração no mundo de mercado. Por isso, para o grupo Archizoom, a cidade contemporânea era o próprio mercado. (BRANZ, 2014)

Esta metáfora foi entendida como uma crítica à urbanística pós-moderna, que não encontrava formas alternativas ao espaço de consumo por excelência: o centro comercial. $E$ foi também uma crítica aos planos urbanos realizados durante os anos 1950-1960, como Chandigah (1951) e Brasília (1956), que, segundo Branzi (1976), eram cidades onde a dimensão da arquitetura era mais importante do que a dimensão humana, que afinal nem existia. Ao contrário de Chandigah, A No-Stop City evita a lógica da hierarquização terri-

Poiésis, Niterói, v. 19, n. 31, jan./jun. 2018. 

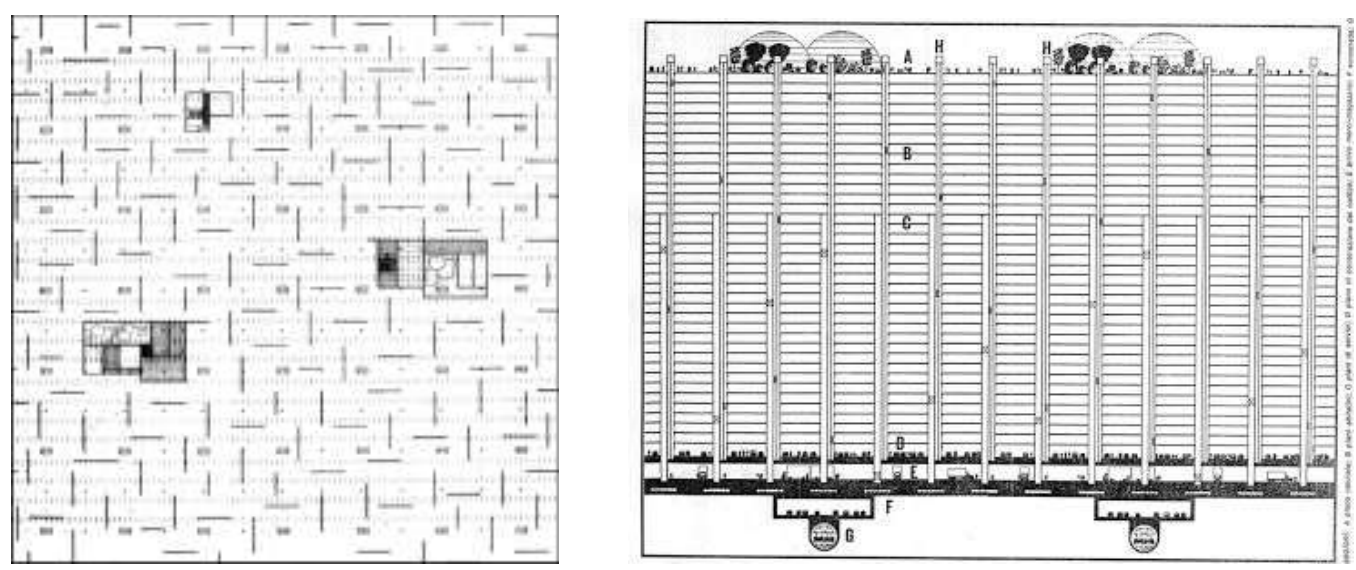

Fig. 4.1 e 4.2 - Archizoom

No-Stop City, 1969, Seção e Planta tipo

(Fonte: BRANZI, Andrea. No-Stop City: Archizoom Associati. Orléans: HYX, D.L., 2001) 
torial existente na metrópole atual através da rejeição do valor representativo da arquitetura. O espaço urbano deixa de ser um conjunto de volumes arquitetônicos e passa a ser um espaço contínuo, sem alçados e sem imagens. A metrópole fica assim resumida a um conjunto de funções e de serviços, passando a representar um sistema de produção, de consumo e de circulação, como um supermercado gigante, onde a arquitetura deixa de ser necessária.

\section{Superstudio e o Monumento Continuo}

O grupo Superstudio foi fundado em Florença, em 1967, por Adolfo Natalini e Cristiano Toraldo Di Francia. Pouco depois, Gian Piero Frassinelli, Roberto e Alessandro Magris e Alessandro Poli se juntam ao grupo. O seu trabalho foi descrito, por Natalini (1971) - o membro que mais se destacou no grupo -, em termos de "arquitetura radical", "antiutopia", "utopia negativa" ou "tática de guerrilha". Uma guerrilha contra os ideais dos CIAM que usava o poder da imagem, da utopia e da ficção para demonstrar que a lógica do discurso modernista, se seguida até suas últimas consequências, iria transformar o mundo em um território totalmente indiferente e homogêneo. (NATALINI, 2005) Assim surgiu o projeto Monumento Continuo, concebido para a Bienal Trigon de Arquitetura e que aconteceu em Graz no outono de 1969. Os meios de representação adotados nessa primeira versão foram fotomontagens extremamente realistas, acompanhadas de uma breve explicação teórica. O projeto era definido por uma série de imagens que representavam uma estrutura infinita, resultante da multiplicação infinita da mesma unidade mínima: o cubo. É a redução da arquitetura e do urbanismo a uma estrutura que se desenvolve a partir de uma malha cartesiana. Um edifício (monumento) que podia percorrer o mundo, cruzando montanhas, rios, cidades. Não sabemos o que acontecia no interior dessa estrutura. Não existem plantas ou seções, apenas imagens exteriores, que mostram um edifício que representa a repetição sistemática da mesma estrutura racional e silenciosa, que percorria todo o planeta sem qualquer diferenciação ou particularidade. Como a lava de um vulcão que vai avançando sobre o território. (Fig. 5 e 6 )

Poiésis, Niterói, v. 19, n. 31, jan./jun. 2018. 

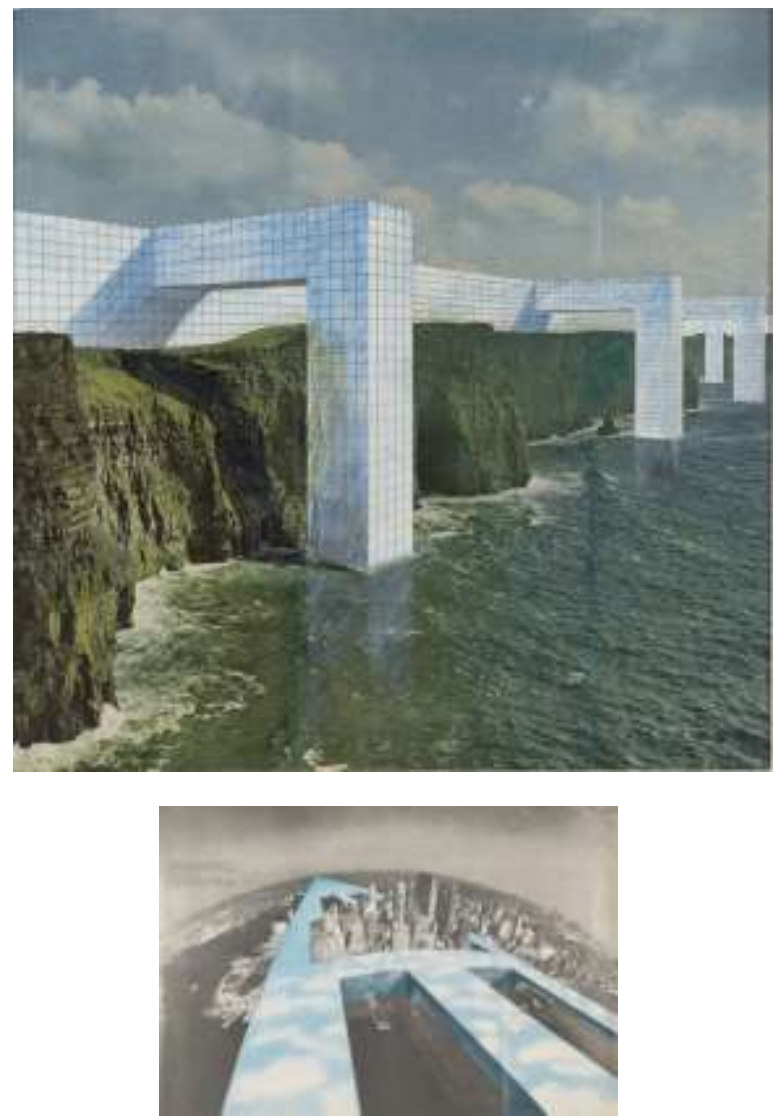

Fig. 5 e 6 - Superstudio

Monumento Continuo, 1969

(Fonte: Architectural Association (c) Superstudio.)

Poiésis, Niterói, v. 19, n. 31, jan./jun. 2018. 
A população que habitava essa estrutura era nômade, sem residência fixa, sem amarras, perambulando pelo mundo sem qualquer tipo de posse ou razão para fixação. É uma visão de liberdade total associada ao urbanismo total, representado em forma de monumento que, segundo Frampton (1997), era um signo urbano que ilustrava um mundo no qual os bens de consumo haviam sido eliminados; uma utopia instrumental que transmitia uma análise profunda e abstrata da sociedade e do problema da arquitetura em sua relação com a metrópole. Neste contexto, podemos dizer que, por um lado o Monumento Continuo é um projeto que lança uma "alerta" sobre o perigo da radicalização dos pressupostos racionalistas dos CIAM; por outro também introduz o desejo de um mundo livre dos interesses capitalistas, do consumo, da política. Um mundo nômade que não reconhece compromissos sociais, diferenças étnicas, políticas, econômicas ou culturais:

Nós tentamos destruir o sistema existente para abrir caminho para o estabelecimento de um novo sistema, livre de divisões, do colonialismo cultural, violência e consumismo. Nós estávamos perseguindo a utopia de um mundo livre e uma vida livre do trabalho, uma vida sem objetos. (NATALINI, 2008, p. 167)

Assim como a No-Stop City, o Monumento Continuo não propõe modelos ou alternativas mas sim uma rejeição ao capitalismo e às suas estruturas de exploração e às contradições que o nacionalismo do movimento moderno originou. Com a forma de uma simples grade estrutural (o cubo), o Monumento Continuo combate tanto a imitação vulgar do modernismo "clássico" - ligada aos experimentos modernos de "casa para uma existência mínima" e "método racional de construção" - quanto o vocabulário monótono de uma galopante arquitetura especulativa de centros comerciais e de condomínios fechados.

Suas propostas de ficção introduziram três importantes possibilidades na disciplina de arquitetura. Primeiro, anulam a diferença entre arquitetura e urbanismo, mostrando que em uma sociedade feita de fluxos e de relações existe um espaço único que deve ser gerido como um todo, que é o espaço da comunicação. Segundo, introduzem a lógica da liberdade, transparência, fluidez espacial e de espaço infinito em oposição à lógica do espaço de-

Poiésis, Niterói, v. 19, n. 31, jan./jun. 2018. 
limitado com muros e paredes. Terceiro, denunciam o fim da arquitetura tradicional, introduzindo uma arquitetura efêmera, em constante movimento.

\section{Considerações à guisa de conclusão}

Na visão de Charles Jencks (2011), o final do modernismo na arquitetura ocorre com a implosão do conjunto habitacional Pruitt-Igoe em julho de 1972. Fortemente inspirado no conceito da Ville Radieuse de Le Corbusier, a queda de Pruitt-Igoe acabou por significar não apenas o fracasso de um projeto de habitação pública, mas também a incapacidade do projeto moderno em resolver os conflitos e as complexidades da sociedade. É neste contexto que Marshall McLuhan (1947), um dos mais controversos intelectuais dos anos sessenta, apresenta uma clara teoria sobre o que caracterizou a arquitetura até aos anos sessenta e o que caracteriza a arquitetura depois dos anos sessenta. Segundo ele, existia uma sociedade visível que foi substituída por uma tátil. A sociedade visível é aquela do Renascimento e da perspectiva, mas também é a sociedade industrial e da máquina. É criada principalmente sobre o significado da medida, da proporção e da quantidade. A sociedade tátil é aquela do consumo, da eletrônica, do poder da imagem, fundada sobre uma sensibilidade intensa, menos ordenada, mas mais vital. A diferença entre as duas sociedades é enorme: a primeira gera quantidade, materiais, geometria, funções e qualidade; a segunda gera fluxos, energia, imagens, relações efêmeras e valores imateriais. É na definição de sociedade tátil que estamos inseridos, na qual já não conseguimos viver sem o telefone celular, sem a internet ou sem os inúmeros aparelhos eletrônicos que preenchem o nosso dia a dia. Parece-nos indispensável estar em comunicação permanente com o mundo. Esta exigência de fazer parte de um circuito e de interagir em um determinado contexto está também presente nos edifícios e nos objetos que nos rodeiam. Se confrontarmos, por exemplo, um edifício do início do século XX com um contemporâneo, percebemos que o primeiro se define por sua massa, pela organização espacial, pelos cheios e vazios, pelo sistema construtivo e funcional. O segundo define-se pela ação que provoca no entorno e no público. 
A arquitetura radical italiana previu o aparecimento de uma nova cultura de projeto inserida dentro da lógica do consumo, da comunicação, da eletrônica, das imagens, dos fluxos e de energias. O princípio de realizar formas de caráter permanente foi substituída pelo princípio da volatilidade e das relações efêmeras no qual a arquitetura, segundo Branzi (1996), deixava de ser um instrumento para alterar a sociedade, passando ela própria a fazer parte dessa sociedade conflituosa e contraditória.

Os grupos radicais italianos, em especial o grupo Archizoom e Superstudio, colocaram em evidência a debilidade da realidade urbana em relação ao sistema capitalista fundamentado no consumo de massas. Suas propostas utópicas idealizaram espaços artificiais, que podiam crescer infinitamente dentro da lógica do centro comercial. Espaços iluminados e climatizados artificialmente onde, no seu interior, qualquer indivíduo poderia acomodar-se como bem entendesse. O objetivo era mostrar a possibilidade de desvincular o indivíduo do espaço tradicional e funcionalista. Ou seja: por um lado, eles radicalizaram as consequências dos ideais modernistas na cidade e na sociedade e, por outro, revelaram a impossibilidade da arquitetura existir no mundo pós-moderno, no qual a potencialidade dos meios eletrônicos de comunicação, da imagem, das sensações e emoções era contrária ao funcionamento estático da própria arquitetura.

Foi o que Rem Koolhaas e Elia Zenghelis propuseram com o projeto Exodus ou os Prisioneiros Voluntários da Arquitetura, em 1972 quando desenharam uma gigantesca macroestrutura que alterava, de forma radical, as relações entre corpo e espaço, arquitetura e cidade, introduzindo novas formas de comportamento e novas formas de vida:

0 Archigram estava no auge de seu poder e grupos como Archizoom e Superstudio concebiam estórias arquitetônicas supondo uma vasta expansão do território da imaginação arquitetônica. [...] “Exodus, ou os Prisioneiros Voluntários da Arquitetura" foi uma reação a essa inocência: um projeto para enfatizar que o poder da arquitetura é mais ambíguo e perigoso. Baseado no estudo "O Muro de Berlim como Arquitetura", Exodus propunha apagar uma seção do centro de Londres para estabelecer ali uma zona de vida metropolitana - inspirada em Baudelaire - e proteger esta zona da cidade antiga com muros, criando 0

Poiésis, Niterói, v. 19, n. 31, jan./jun. 2018. 
máximo de divisão e contraste. As pessoas em Londres poderiam escolher: aqueles que desejassem ser admitidos nesta zona de hiperdensidade se tornariam "Os Prisioneiros Voluntários da Arquitetura". (KOLHAAS apud SCOTT, 2003, p. 89)

Assim como a arquitetura radical italiana, Kolhaas produziu um projeto utópico, cuja intenção não era ser construído, mas sim provocar uma crítica ao modelo de cidade existente. Ele não surge como proposta ou como alternativa à realidade, mas como um importante instrumento teórico, de investigação e de estudo sobre as novas condições humanas e urbanísticas. Por um lado ele chama a atenção para o perigo da arquitetura e do urbanismo modernos e, por outro, emprega as duas ideologias do capitalismo e do consumismo para criar uma cidade contínua e infinita, muito à imagem das propostas dos "grupos radicais italianos". (Fig. 7)

Mais do que definir um modo de desenhar as cidades, as utopias produzidas nos anos 1960 e 1970 colocaram em evidência que o conceito tradicional de crescimento urbano, que partia da evolução aldeia-vila-cidade-metrópole, estava completamente equivocado. Segundo Branzi (2006), não se podia pensar que a metrópole era o crescimento de uma aldeia ou de uma pequena cidade. Os pontos de referência válidos para uma pequena cidade não são os mesmos que para uma metrópole. As praças, as fontes, as pequenas igrejas, as casas, as esquinas que existem na aldeia não podem existir na metrópole, porque são contrárias a elas e por isso bloqueiam o seu desenvolvimento.

Por outro lado, a arquitetura não devia fazer parte da metrópole, porque é um fenômeno estático, muito contrário ao funcionamento da própria metrópole e, por isso, também ela (a arquitetura) bloqueia o seu funcionamento. Outra parte do desastre da metrópole, ainda segundo Branzi (2006), está no ser humano que frequentemente tenta diminuir a distância entre cidade e metrópole. Ele coloca um vaso com flores na janela do arranhacéus, fontes nas entradas dos grandes edifícios comerciais e de escritórios, adornos nas estruturas pré-fabricadas. Estas operações, de tentar identificar a metrópole através dos cânones tradicionais, são inúteis e impedem o natural crescimento físico e intelectual da metrópole. 


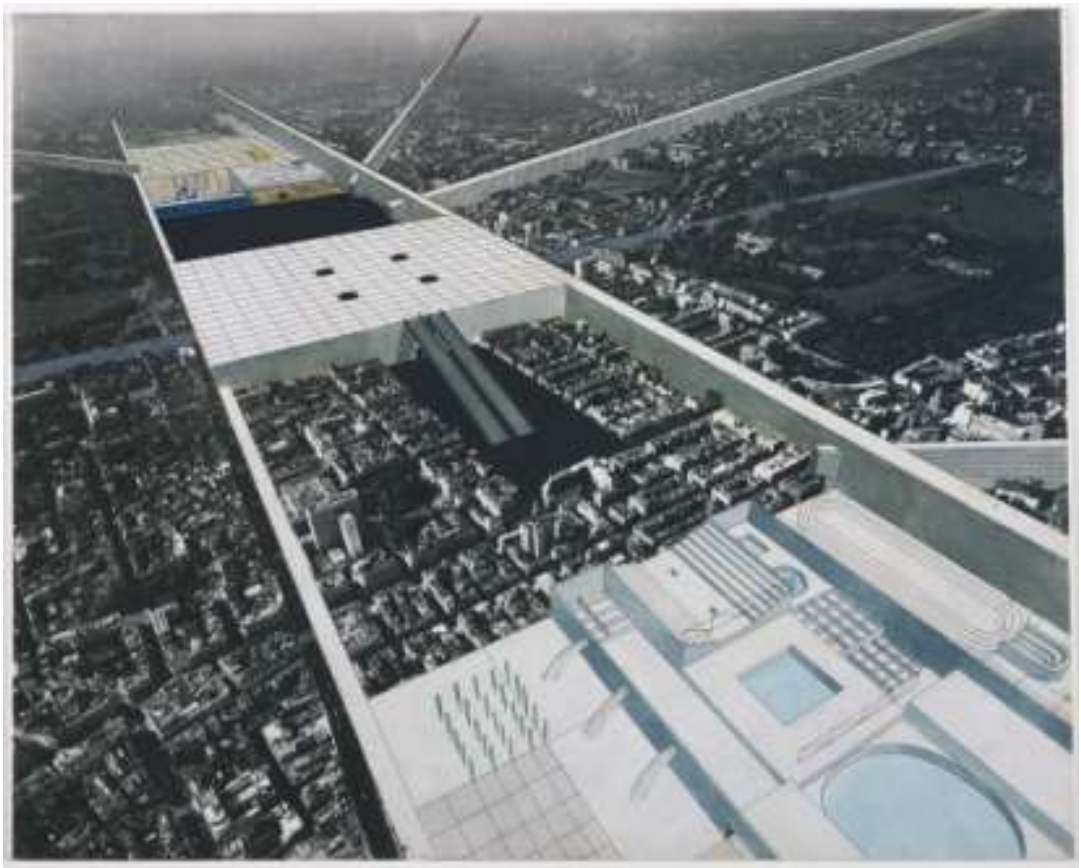

Fig. 7 - Projeto Exodus

Rem Koolhaas e Elia Zenghelis, 1972

(Fonte: O.M.A.: Exodus,1972. Architectural Design, Londres, v. 47, n. 5, 1977)

Poiésis, Niterói, v. 19, n. 31, jan./jun. 2018. 
As propostas utópicas tanto dos Archizoom como dos Superstudio tentam estimular novas aproximações ao conceito de metrópole na qual a estratificação homogênea das diferentes funções existe de modo completamente contrário à cidade oitocentista - na qual a arquitetura estava em equilíbrio com a envolvente. Este equilíbrio não existe na metrópole atual, onde cada função tem sua própria autonomia, totalmente independente do edifício que está ao seu lado. Ao reconhecer no fenômeno urbano o ponto mais fraco de todo o sistema industrial, a arquitetura radical italiana faz uma crítica ao conceito de metrópole tradicional, que deveria ser o símbolo máximo do progresso, mas, ao contrário, continua sendo o lugar mais confuso e mais contraditório da sociedade atual.

\section{Referências}

BRANZI, Andrea. La casa calda, esperienze del nuovo design italiano. Milão: Idea Books, 1999.

BRANZI, Andrea. Tecnologia sotto accusa. Rassegna, Milão, n. 38/39, p. 36-39, 1976.

BRANZI, Andrea. No-Stop City: Archizoom Assoaciati. França: HYX, 2006.

COOK, Peter. Archigram. Londres: Studio Vista Publishers, 1972.

FRAMPTON, Kenneth. História crítica da arquitetura moderna. São Paulo: Martins Fontes, 1997.

JENCKS, Charles. The Story of Post-Modernism: Five Decades of the Ironic, Iconic and Critical in Architecture. New Jersey: John Wiley \& Sons, 2011.

SCOTT, Felicity D. Involuntary prisoners of architecture. October, Cambridge, n. 106, p. 75-101, set.-dez. 2003.

LYOTARD, Jean-François. A Condição Pós-Moderna. Lisboa: Gradiva, 1989.

MCLUHAN, Marshall. The Medium is the Massage: An inventory of effects. Londres: Penguin Books, 1967. 
NATALINI, Adolfo. Superstudio: the middelburg lectures. Amsterdam: De Vleeshal and Zeeuws Museum, 2005.

PAPANEK, Victor. Arquitectura e design. Lisboa: Edições 70, 1995.

PUGLISI, Luigi Prestinenza. This is Tomorrow, avanguardie e architettura contemporanea. Torino: Testo \&lmmagine, 1999.

RATTAZZI, Cristina. Militanza Tra Teoria e Prassi. Milão: FrancoAngeli, 1997.

ROUILLARD, Dominique. Archigram. In DETHIER, Jean (Org.) La Ville: art et architecture en Europe, 1870-1993. Paris: Editions du Centre Pompidou, 1994.

TAFURI, Manfredo. Storia dell' Architettura Italiana. Torino: Einaudi, 1986.

VENTURI, Robert; BROWN, Denise Scott. Complexidade e Contradição em Arquitetura. São Paulo: Martins Fontes, 1982.

\section{Notas}

\footnotetext{
${ }^{1} \mathrm{O}$ termo Arquitetura Radical Italiana foi utilizado pela primeira vez pelo crítico de arquitetura Germano Celant em 1972, para descrever a pesquisa de vanguarda que emergia no meio acadêmico de Florença, em 1966.
} 